\title{
Produção de melão rendilhado em sistema hidropônico com rejeito da dessalinização de água em solução nutritiva
}

\author{
Nildo da S. Dias ${ }^{1}$, Raniere B. de Lira', Raimundo F. de Brito ${ }^{1}$, \\ 0 svaldo $N$. de Sousa Neto ${ }^{1}$, Miguel Ferreira Neto ${ }^{1} \&$ André M. de Oliveira ${ }^{1}$
}

\begin{abstract}
RESUMO
Desenvolveu-se esta pesquisa visando o aproveitamento do rejeito da dessalinização da água no cultivo hidropônico do meloeiro. 0 experimento foi conduzido no Departamento de Ciências Ambientais da UFERSA, localizado no município de M ossoró, $\mathrm{RN}$, em vasos com substrato de fibra de coco sob condições protegidas. 0 delineamento experimental utilizado foi blocos ao acaso, com 3 repetições cujos tratamentos corresponderam a cinco níveis de sal inidade da solução nutritiva obtidos com ou sem a necessidade de diluição do rejeito da dessalinização da água $(2,1 ; 3,6 ; 4,9 ; 6,0$ e 7,0 dS m-1). Avaliaram-se: altura de plantas, diâmetro de colo, área foliar, rendimento total e comercial de frutos por planta e, ainda, peso médio de frutos comerciais e totais. Em geral, as variáveis estudadas decresceram linearmente com o incremento da salinidade da solução nutritiva demonstrando que a salinidade da solução com água de rejeito reduz a disponibilidade de água para as plantas, devido ao efeito osmótico.
\end{abstract}

Palavras-chave: Cucumis melo L. ambiente protegido, água salina

\section{Melon yield in a hydroponic system with wastewater from desalination plant added in the nutrient solution}

\begin{abstract}
To use of waster water from desalting in the hydroponic cultivation, an experiment was carried out at the D epartment of Environmental Science of the Universidade Federal Rural do Semi-Árido-UFERSA, in the municipal district of Mossoró-RN, in pots with substrates of coconut fiber under greenhouse conditions. The experimental design was in randomized blocks, with three repetitions. Treatments were composed of five levels of salinity of the nutrient solution obtained with, and without, dilution of the waster water from desalting $\left(2.1,3.6,4.9,6.0\right.$ and $\left.7.0 \mathrm{dS} \mathrm{m}^{-1}\right)$. The variables plant height, stem diameter, leaf area, mean weight of fruit and total and marketable yield were detemined. In general, the variables decreased linearly with the increase of the salinity of the nutrient solution, showing that the salinity with waster water from desalting reduces the absorption of water by the plants due to the osmotic effect.
\end{abstract}

Key words: Cucumis melo L., greenhouse, water saline 


\section{INTRODUÇÃO}

No semiárido brasileiro o desafio, devido à escassez de águas superficiais, é promover o abastecimento de água às famílias rurais e garantir a produção de alimentos. O uso de águas subterrâneas é uma alternativa viável para garantir o acesso dessas comunidades à água, a partir de investimentos públicos na perfuração de poços tubulares. Entretanto, essas fontes hídricas apresentam, na maioria dos casos, restrições de uso para o consumo humano por apresentarem problemas de salinidade (Ayers \& Westcot, 1999). O tratamento amplamente utilizado para reduzir a concentração de sais dessas águas tem sido a dessalinização por osmose reversa (Porto et al., 2001). Muitas comunidades rurais de Mossoró, $\mathrm{RN}$, são abastecidas com água proveniente do aquífero Jandaíra, de elevada concentração de sais (Medeiros et al., 2003), a qual é tratada em dessalinizadores, possibilitando sua utilização para consumo humano.

Independe da eficiência da membrana e da estrutura instalada dos dessalinizadores, o sistema de osmose reversa produzirá sempre a água potável mas, também, a água residuária (rejeito, salmoura ou concentrado) estimada em aproximadamente $60 \%$ da água bruta tratada por osmose reversa, com concentração de sais superior à salinidade da água original. Em geral, os cursos d'água e o solo são os principais meios para a deposição do rejeito salino, o que tem causado impactos negativos ao ambiente das comunidades que se beneficiam desta tecnologia. Portanto, o grande desafio da utilização do sistema de tratamento de água com osmose reversa reside na deposição adequada ou sua reutilização para a produção de alimentos.

Conforme Mickley (2004), a escolha da melhor opção para se dispor do rejeito da dessalinização da água deve atender às disponibilidades locais (terra, compatibilidade das águas receptoras e distância), às disponibilidades regionais (geologia, leis estaduais, geografia e clima), ao volume de concentrado, aos custos envolvidos, à opinião pública e à permissibilidade. Soares et al. (2006) sugerem o uso da água do rejeito para o cultivo de plantas tolerantes à salinidade em recipientes de cultivo, com o que se evitaria o acúmulo dos sais no ambiente visto que estes seriam levados com o recipiente de cultivo, durante sua comercialização.

Outra opção para se dispor do rejeito salino é a sua utilização na solução nutritiva em cultivos hidropônicos de hortaliças, uma vez que a tolerância das plantas à salinidade em sistemas hidropônicos é maior em relação ao sistema convencional, pois a inexistência do potencial mátrico, superando o potencial total da água, reduzirá a dificuldade de absorção de água pelas plantas (Soares et al., 2007); por outro lado, a própria estrutura hidropônica funciona como sistema de drenagem e os sais acumulados ao final do cultivo podem ser facilmente descartados para fora do sistema; desta forma, os sistemas hidropônicos permitem o uso das águas de rejeito dos dessalinizadores, viabilizando uma atividade produtiva geradora de renda para as comunidades rurais, com maior segurança ambiental.

Além do sistema de cultivo a tolerância das plantas à salinidade também pode ser influenciada por outros fatores, incluindo-se o estágio de crescimento, o tempo e a duração da exposição, condição ambiental, tipo de substrato (Adams, 1991).

Com esta hipótese é que um experimento foi conduzido para avaliar a tolerância do meloeiro a salinidade da água do rejeito da dessalinização por osmose reversa nas comunidades rurais de Mossoró, RN, em hidroponia. Neste sentido se objetivou, no presente trabalho, avaliar a produção de melão rendilhado em sistema hidropônico em fibra de coco, com a adição de água de rejeito da dessalinização na solução nutritiva.

\section{MATERIAL E MÉTODOS}

O experimento foi conduzido com a cultura de melão $(C u$ cumis melo L.) do tipo cantaloupe, cultivar AF 015, no período de agosto a novembro de 2008, em sistema hidropônico de cultivo, sob condições protegidas, no campus da Universidade Federal Rural do Semiárido, Mossoró, RN (5 11' S, $37^{\circ} 20^{\prime} \mathrm{W}$ e altitude $18 \mathrm{~m}$ ). Segundo a classificação de Koppen, o clima de Mossoró é do tipo BSwh', isto é, seco, muito quente e com estação chuvosa no verão atrasando-se para o outono, apresentando temperatura média anual de $27,4^{\circ} \mathrm{C}$, precipitação pluviométrica anual bastante irregular, com média de $673,9 \mathrm{~mm}$ e umidade relativa de $68,9 \%$.

A quantidade de fertilizantes adicionados no preparo das soluções nutritivas ( $\mathrm{pH}=6,0)$ utilizadas no experimento, foi suficiente para atender às necessidades nutricionais da cultura do meloeiro, conforme recomendação de Santos (2002), sendo dissolvidos, por cada $100 \mathrm{~L}$ de água, $805 \mathrm{~g}$ nitrato de cálcio, $334 \mathrm{~g}$ nitrato de potássio, $175 \mathrm{~g}$ de fosfato monoamônico - MAP, 252 g sulfato de magnésio e 10 g Quelatec (mistura sólida de micronutrientes contendo ferro, magnésio, zinco, boro e molibdênio, respectivamente). Obtiveram-se as águas das soluções nutritivas com o rejeito da dessalinização da água, diluída ou não com água de abastecimento $\left(\mathrm{D}_{1}\right.$ = água de abastecimento, $\mathrm{D}_{2}=25 \%$ água de rejeito $+75 \%$ água de abastecimento, $\mathrm{D}_{3}=50 \%$ água de rejeito $+50 \%$ água de abastecimento, $\mathrm{D}_{4}=75 \%$ água de rejeito $+25 \%$ água de abastecimento e $\mathrm{D}_{5}=$ água de rejeito) que, após a adição dos fertilizantes, apresentavam condutividades elétricas iguais, respectivamente, a 2,$1 ; 3,6 ; 4,9 ; 6,0$ e 7,0 dS m${ }^{-1}$, constituindo-se os cinco tratamentos experimentais aleatorizados em blocos com quatro repetições.

A água de rejeito do dessalinizador foi coletada na comunidade Puxa Boi, localizada em Mossoró, RN, enquanto a água de abastecimento proveio do campus da UFERSA. As características químicas das águas de rejeito, abastecimento e as diluições utilizadas no experimento, são descritos na Tabela 1

A área experimental foi constituída de 6 fileiras de plantas, sendo as 2 fileiras da extremidade designadas como bordadura. Os mourões foram instalados nas extremidades de cada fileira para amarração de 3 fios de arame com o intuito de tutorar as plantas das parcelas. Cada parcela experimental se compunha de dois sacos plásticos de 12 L cada um, contendo uma camada de $2 \mathrm{~cm}$ de brita no fundo, recoberta com 
Tabela 1. Análise das águas utilizadas na solução nutritiva

\begin{tabular}{|c|c|c|c|c|c|c|c|c|c|}
\hline \multirow{2}{*}{ Mistura } & \multirow{2}{*}{$\mathrm{CE}\left(\mathrm{dS} \mathrm{m}^{-1}\right)$} & $\mathrm{pH}$ & $\mathrm{Ca}$ & $\mathrm{Mg}$ & $\mathrm{Na}$ & $\mathrm{Cl}$ & $\mathrm{CO}_{3}$ & $\mathrm{HCO}_{3}$ & */mm 1 1-10.5 \\
\hline & & \multicolumn{8}{|c|}{$\mathrm{mmol} \mathrm{L}^{-1}$} \\
\hline $\mathrm{D} 1$ & 0,46 & 8,0 & 0,6 & 0,1 & 5,1 & 1,8 & 0,5 & 3,8 & 8,62 \\
\hline D2 & 2,23 & 7,8 & 6,2 & 4,6 & 7,7 & 12,4 & 0,6 & 5,2 & 3,30 \\
\hline D3 & 3,78 & 7,6 & 11,6 & 8,2 & 16,8 & 26,0 & 0,7 & 5,7 & 5,34 \\
\hline D4 & 5,02 & 7,6 & 16,5 & 9,1 & 23,9 & 41,4 & 0,7 & 6,4 & 1,87 \\
\hline D5 & 5,96 & 7,4 & 22,4 & 8,6 & 39,6 & 64,6 & 0,3 & 8,1 & 10,06 \\
\hline
\end{tabular}

*Relação de Adsorção de Sódio

telado de nylon e preenchidos com $8 \mathrm{~kg}$ de fibra de coco. Os sacos foram posicionados de forma que as plantas ficassem espaçadas $0,50 \mathrm{~m}$ dentro das fileiras e 1,00 m entre fileiras de plantas.

As parcelas experimentais foram alocadas em um ambiente protegido com cobertura em arco, com 6,4 m de largura, 22,5 m de comprimento e pé direito de 3,0 m, coberta com filme de polietileno de baixa densidade com aditivo anti-ultravioleta e espessura de $150 \mathrm{~m}$, protegida nas laterais com malha negra $50 \%$.

As mudas foram produzidas em bandejas de poliestireno expandidas, de 128 células preenchidas com substrato de fibra de coco, as quais flutuavam em solução nutritiva na mesa de germinação. Realizou-se o transplante das mudas aos 10 dias após a semeadura colocando-se, aleatoriamente, duas mudas de melão por cada parcela experimental.

A condução da cultura foi feita com espaldeiras verticais de $2 \mathrm{~m}$ de altura, com auxílio de fita de ráfia, eliminando-se os excessos de brotação lateral até o $9^{\circ}$ ramo (entre 0,6 a $0,7 \mathrm{~m}$ do colo da planta) por meio de podas, deixando-se os demais brotos com cinco folhas. Utilizou-se, na poda, tesoura apropriada para cortes em hastes tenras, com posterior tratamento fitossanitário, evitando a entrada de patógenos, pelos ferimentos. Os frutos foram acondicionados em cestas plásticas (enredadas), presos à linha de arame, para ajudar a sustentação nas plantas e conferir melhor qualidade de casca, permitindo bom desenvolvimento dos frutos selecionados (raleio) ao longo do ciclo da cultura; após o raleio se deixaram 2 frutos por planta.

A irrigação foi feita por inundação utilizando-se uma proveta graduada e se mantendo a umidade sempre a capacidade máxima do 'recipiente', definida como a quantidade de água que permanece no substrato logo após a drenagem do excesso de água. Calculou-se o volume de água aplicado com base nos dados de umidade atual do substrato, obtidos com tensiômetros instalados a $20 \mathrm{~cm}$ de profundidade e da curva característica de retenção de água da fibra de coco, construída previamente.

A polinização foi melitófila e espontânea, ou seja, durante a fase de florescimento as abelhas adentravam no ambiente protegido. A colheita dos frutos foi realizada aos 62 DAT, quando atingiram o ponto de maturação fisiológica, isto é, mudança de coloração da casca para acinzentada e rendilhamento em volta do pedúnculo.

Foram estimados, durante o experimento, a altura das plantas e o diâmetro do caule utilizando-se uma régua graduada e um paquímetro digital. No final do ciclo, foram estimados: a área foliar (AF) das plantas de cada parcela experimental, uti- lizando-se o integrador de área foliar modelo LI-3100; o peso de matéria fresca da parte aérea (MFPA), através de balança de precisão e o peso de matéria seca da parte aérea (MSPA), pelo peso seco em estufa com circulação forçada de ar a 70 ${ }^{\circ} \mathrm{C}$, até atingir peso constante.

Para as análises de produção e os componentes de produção utilizaram-se todos os frutos da área útil da parcela e se avaliaram o peso médio de frutos (PMF), expresso em $\mathrm{g}$ fruto $^{-1}$, e a espessura da polpa (EP), em mm; determinaram-se, também, o pH dos frutos e os sólidos solúveis totais ( $\left.{ }^{\circ} \mathrm{Brix}\right)$ com refratômetro digital e compensação de temperatura automática.

Os resultados obtidos foram submetidos a análise de variância do software SISVAR, utilizando-se a análise de regressão e o teste de médias para as variáveis coletadas, com base no teste de Tukey a $5 \%$ de probabilidade.

\section{RESULTADOS E DISCUSSÃO}

\section{Parâmetros de crescimento}

O efeito da condutividade elétrica da solução nutritiva sobre a altura de plantas de melão foi de natureza quadrática sendo que os efeitos negativos da redução do potencial osmótico ocorreram a partir dos níveis de salinidade da solução nutritiva 4,$61 ; 2,06$ e $2,43 \mathrm{dS} \mathrm{m}^{-1}$ durante as fases de crescimento (20 DAT), florescimento (35 DAT) e frutificação (50 DAT), respectivamente (ponto de máximo das equações de regressões da Figura 1A). Vários autores reportam o efeito quadrático da salinidade sob a altura das plantas, principalmente quando a salinização do solo advém do excesso de adubos da fertirrigação sob condições protegidas, conforme relatado por Dias et al. $(2005 ; 2006)$ para a cultura da alface e do melão, respectivamente. Esses autores atribuem tal comportamento ao incremento de fertilizantes no solo acarretar em consumo de luxo de nutrientes pela cultura e consequente aumento do crescimento das plantas com o incremento da CEs, até o ponto de máximo da curva, compensando o efeito negativo da redução do potencial osmótico da solução. Contrariamente, Eloi et al. (2007) verificaram, nas mesmas condições de cultivo, para a cultura do tomate, decréscimo linear na altura das plantas com o incremento da salinidade inicial do solo causada por excesso de adubo.

No presente estudo o efeito quadrático da salinidade em relação à altura das plantas é, devido, provavelmente, aos efeitos benéficos dos sais presentes na água de rejeito da dessalinização da água, sobretudo o cálcio e o magnésio, até o ponto de máximo da curva, quando o efeito osmótico se sobrepõe ao nutricional das plantas; isto pode ocorrer pela toxidez de íons específicos ou pela dificuldade de absorção de água no substrato.

O diâmetro do colo diferiu significativamente entre os níveis de salinidade da solução nutritiva apenas nas leituras aos 35 e 50 DAT, com efeito da condutividade elétrica da solução nutritiva sobre o diâmetro do colo de natureza quadrática (Figura 1B). Dias et al. (2006) verificaram, trabalhando com melão em ambiente protegido, que o diâmetro do colo 


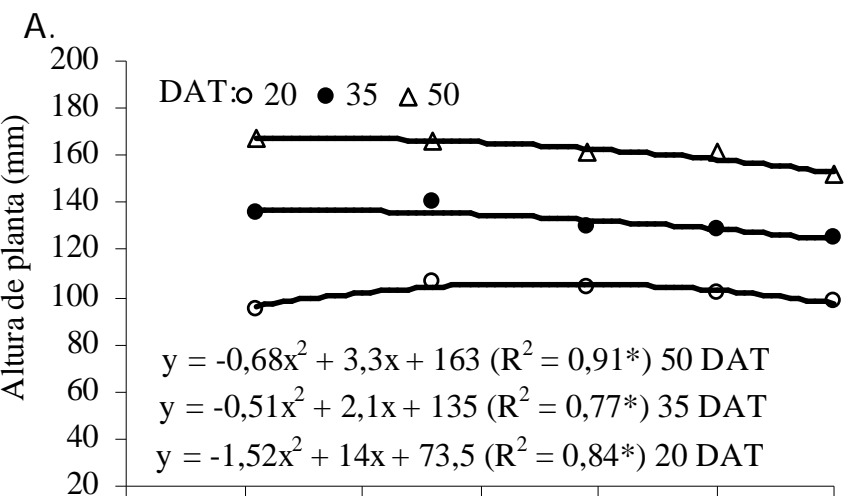

B.

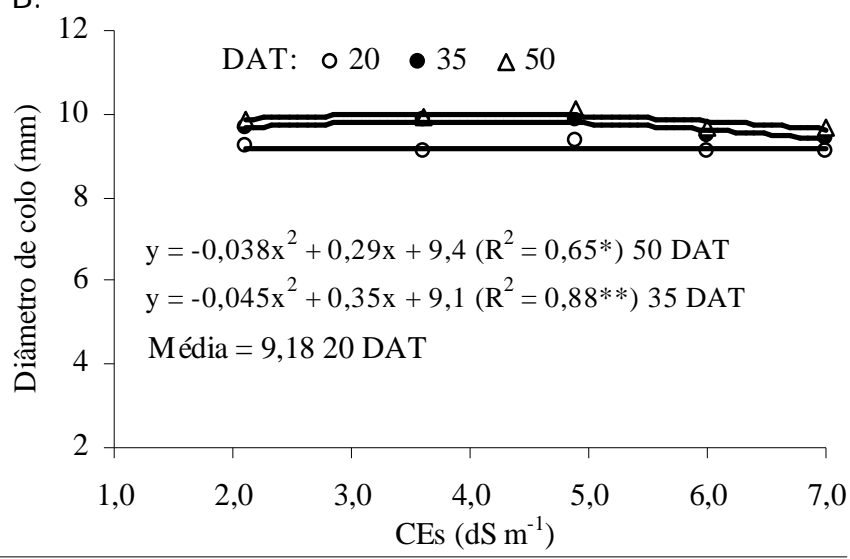

Figura 1. Altura e diâmetro do colo de plantas do melão em função da salinidade da solução nutritiva com adição de rejeito salino

foi afetado linearmente pela salinidade inicial do solo, em todas as medições efetuadas, exceto aos 34 DAT, quando houve efeito quadrático

Com relação ao parâmetro área foliar, em termos absolutos os efeitos dos níveis de salinidade da solução nutritiva podem ser representados por meio da estimativa da equação linear, em que se verifica decréscimo da AF com o incremento da salinidade da solução nutritiva (Figura 2A). Quando se compara a AF das plantas de melão nutridas com solução de $\mathrm{CE}_{\mathrm{s}}=2,1 \mathrm{dS} \mathrm{m}^{-1}$ (testemunha) com as de maior salinidade preparada com $100 \%$ de água de rejeito $\left(\mathrm{CE}_{\mathrm{s}}=7 \mathrm{dS} \mathrm{m}{ }^{-1}\right)$, verifica-se perda de 23\%. Dias et al. (2005), estudando os efeitos da salinidade do solo causada pelo excesso de adubo no crescimento do meloeiro, verificaram respostas quadráticas para a variável área foliar em todas as fases da cultura. Em termos relativos e com base na curva típica de tolerância à salinidade do meloeiro (Figura 2A) pode-se verificar valores de salinidade limiar da solução nutritiva (SL) de $3,01 \mathrm{dS}^{-1}$ para a AF com perda relativa (b) por incremento unitário da $\mathrm{CE}_{\mathrm{s}}$ acima da SL, iguais a $4,01 \%$ por $\mathrm{dS} \mathrm{m}^{-1}$.

Para Taiz \& Zeiger (2006), a redução do potencial osmótico do substrato atua de forma negativa sobre o processo fisiológico, reduzindo a absorção de água pelas raízes, inibindo a atividade meristemática, o alongamento celular e, como consequência, redução no crescimento e desenvolvimento das plantas. Desta forma, a redução na $\mathrm{AF}$, como consequência do estresse salino, pode representar a inabilidade das plantas para discriminar entre os estresses hídrico e salino (Bin-

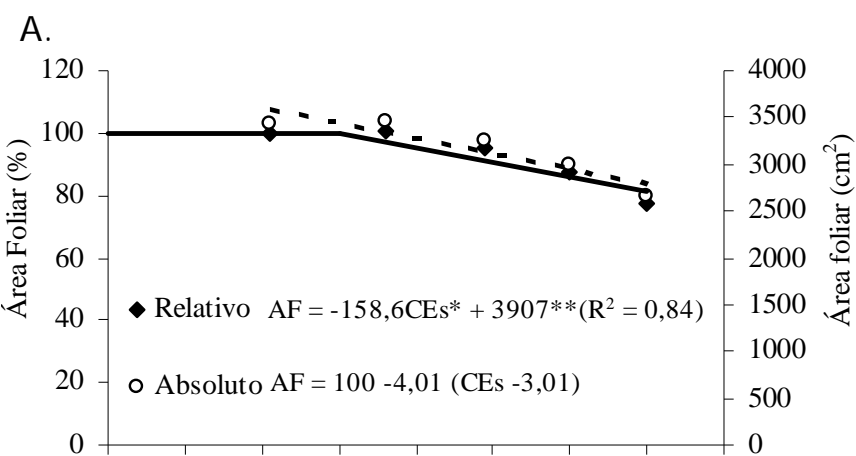

B.

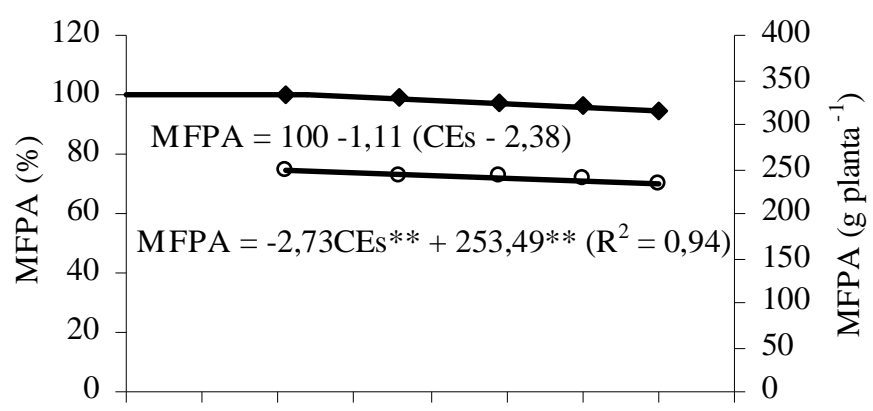

C.

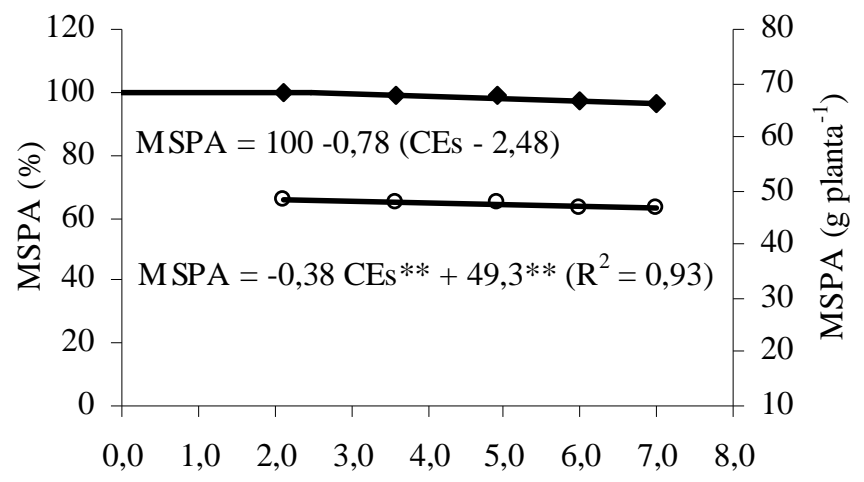

CEs $\left(\mathrm{dS} \mathrm{m} \mathrm{m}^{-1}\right)$

Figura 2. Área foliar (A), matéria fresca (B) e seca (C) da parte aérea foliar absoluta e relativa de plantas do melão em função da salinidade da solução nutritiva com adição de rejeito salino

zel et al., 1985) ao invés de um mecanismo de adaptação. Algumas espécies vegetais em meios salinos usam estratégias de alterações morfológicas e anatômicas para superar a deficiência hídrica e essas mudanças incluem a redução do tamanho e o número de folhas, diminuição do número de estômatos, alteração na distribuição das folhas, aumento na grossura da cutícula foliar e diminuição da diferenciação e do desenvolvimento do tecido vascular.

Tem-se, na Figura 2B e C, respectivamente, uma relação linear entre MSPA e a MFPA com CE da solução nutritiva de modo que, ao se aumentar a CEs, há uma queda significativa na produção de biomassa da parte aérea das plantas. Quando se comparam os resultados das variáveis estudadas obtidos na testemunha $\left(\mathrm{CE}_{\mathrm{s}}=2,1 \mathrm{dS} \mathrm{m}^{-1}\right)$ com o tratamento com solução nutritiva preparada com $100 \%$ de água de rejeito $\left(\mathrm{CE}_{\mathrm{s}}\right.$ $=7 \mathrm{dS} \mathrm{m}^{-1}$ ), verificam-se perdas relativas de 6 e $4 \%$ para as variáveis de crescimento MFPA e MSPA, respectivamente. Em termo relativo, pode-se verificar que valores de salinidade li- 
miar da solução nutritiva (SL) do meloeiro variaram de 2,38 e $2,48 \mathrm{dS} \mathrm{m}^{-1}$ para as variáveis MFPA e MSPA, respectivamente, com perda relativa (b) nas variáveis MFPA e MSPA por incremento unitário da $\mathrm{CE}_{\mathrm{S}}$ acima da SL, igual a 1,11 e 0,78\% por $\mathrm{dS} \mathrm{m}^{-1}$ (Figura 2B e C, respectivamente).

As perdas relativas dessas variáveis refletem o efeito negativo do potencial osmótico da solução nutritiva sobre o crescimento do meloeiro em sistema hidropônico inibindo a absorção de água pela planta, porém os baixos valores de ' $b$ ' das equações de tolerância encontrados indicam que a matéria fresca e seca da parte aérea do meloeiro decrescem suavemente com o incremento da salinidade da solução nutritiva, constatando-se a maior tolerância do meloeiro quando cultivado em substrato, em relação aos valores comumente encontrados na literatura. Por sua vez, em plantas de melão cultivadas em solos sob estresse osmótico. Alencar et al. (2003) encontraram redução na área foliar de $7,44 \%$ por dS m $\mathrm{m}^{-1}$.

\section{Parâmetros de produção e qualidade}

O rendimento do melão foi significativamente influenciado pelos níveis de salinidade da solução nutritiva. As variáveis de produção foram reduzidas linearmente com o incremento da salinidade da solução nutritiva observando-se reduções nas variáveis espessura de polpa (EP) e peso médio de frutos (PMF) das plantas nutridas com solução de 5,5 $\mathrm{dS} \mathrm{m} \mathrm{m}^{-1}$ em relação ao tratamento testemunha, variando de 13,01 e 38,04\% (Figura 3). Pode-se constatar que as variáveis de produção (PMF e EP) foram mais afetadas pelos efeitos da salinidade da água de rejeito na solução nutritiva quando
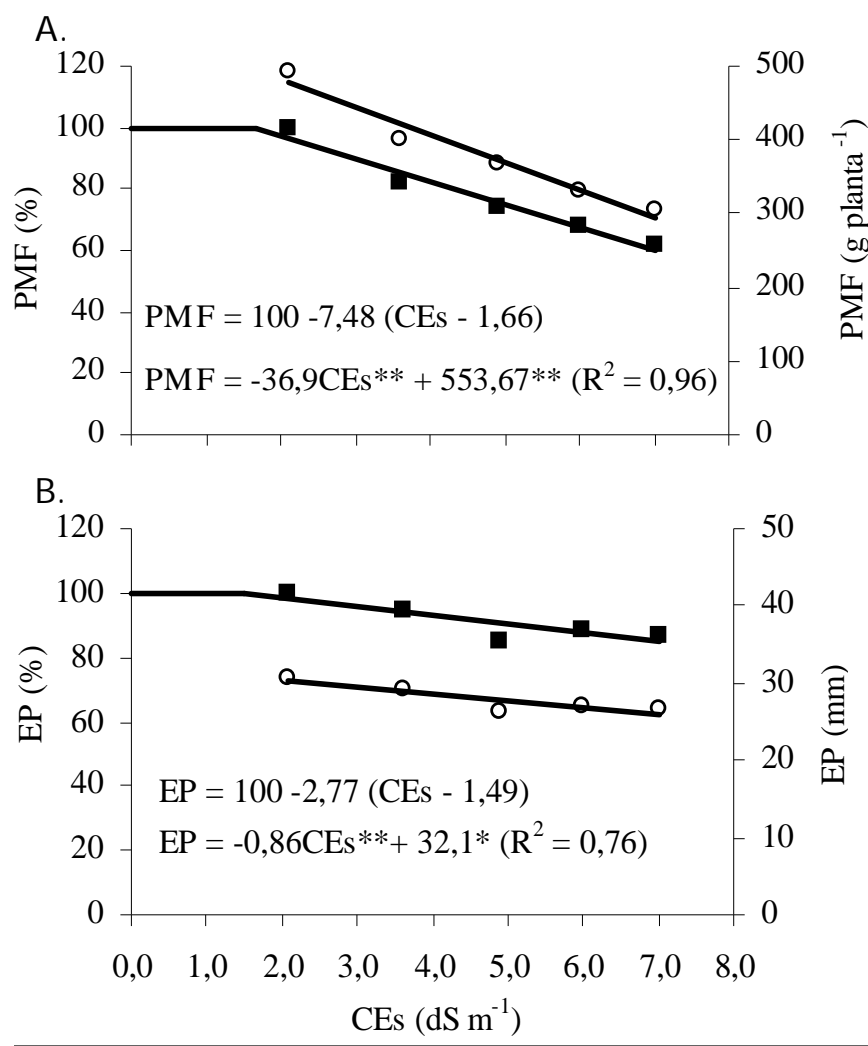

Figura 3. Peso médio de frutos (A) e Espessura de polpa (B) absoluto e relativo de melão em função da salinidade da solução nutritiva com adição de rejeito salino comparadas com as variáveis de crescimento, as quais se mostraram muito sensíveis aos efeitos da salinidade.

A salinidade limite da cultura para o parâmetro PMF foi de $1,66 \mathrm{dS} \mathrm{m}^{-1}$ com perda relativa por incremento unitário da CEs de $7,487 \%$ por dS m$~^{-1}$. Para o melão rendilhado (cv. Bônus II) em cultivo protegido, Dias et al. (2006) registraram perdas de peso médio de frutos de $14,24 \%$ por $\mathrm{dS} \mathrm{m}^{-1}$ acima da salinidade limiar; já Medeiros et al. (2008) citam, para a cultura do melão (cv. Orange flash) irrigado com água salobra, perdas de rendimento relativas de $11,37 \%$ por $\mathrm{dS} \mathrm{m}^{-1}$ para o cultivo tradicional nas condições de Mossoró, RN, comprovando que a salinidade reduz a disponibilidade de água e nutrientes às plantas, provocando perdas de peso médio de frutos à medida em que a concentração salina aumenta. De acordo com Medeiros et al. (2008) a redução no rendimento total dos frutos com o aumento da salinidade é avaliada pelo efeito dos tratamentos nos componentes de produção e no índice de falha do stand.

O efeito reduzido da salinidade da solução nutritiva sobre as variáveis de crescimento e produção do melão, pode ser atribuído ao sistema de cultivo em fibra de coco, visto que a alta capacidade de absorção hídrica deste substrato, cerca de $85 \%$ de umidade, diminuiu a concentração de sais na solução nutritiva e, consequentemente, os efeitos negativos da salinidade sobre o crescimento das plantas; além disso, o uso do substrato torna o potencial matricial inerte não interferindo na força de retenção de água e, em contrapartida, reduz a dificuldade de absorção de água pelas plantas do meio.

Os níveis de salinidade da solução nutritiva afetaram significativamente $(\mathrm{p}<0,05)$ a qualidade química dos frutos, no que se refere aos conteúdos médios de sólidos solúveis totais (SST) e pH, não influenciando a acidez total titulável (ATT), observando-se decréscimo linear dessas variáveis com o incremento da CEs (Figura 4A). Muitos países adotam os valores do conteúdo de SST como referência de mercado para aceitabilidade, com variação mínima de 8 a $10^{\circ}$ Brix; entretanto, se este caráter for analisado isoladamente como atributo de qualidade, poderá ser falho (Morais et al., 2009); apenas os frutos das plantas nutridas com solução de $7 \mathrm{dS} \mathrm{m}^{-1}$ ficaram com valores médios de SST abaixo do mínimo exigido pelo mercado.

Welles \& Buitelaar (1988) verificaram que o conteúdo de sólidos solúveis diminui significativamente com a diminuição da área foliar, isto é, quanto maior a área foliar de plantas maior também sua capacidade fotossintética; fato que, provavelmente, explica o decréscimo linear dos SST dos frutos com o aumento dos níveis de salinidade da solução nutritiva. Medeiros et al. (2008), estudando três níveis de salinidade de água de irrigação em campo, observaram efeito linear positivo sobre os SST dos frutos do meloeiro em virtude do incremento da salinidade. De modo contrário, Dias \& Duarte (2005) concluíram que a tendência foi diminuir de 11,4 para $10,8 \%$, o conteúdo de SST ao se aumentar a salinidade da água de irrigação, ou seja, o estresse osmótico reduziu o conteúdo de sólidos solúveis dos frutos de meloeiro rendilhado (cv. Bônus II).

Com relação ao $\mathrm{pH}$ do fruto, o efeito da salinidade da solução nutritiva pode ser representado por meio de uma equa- 


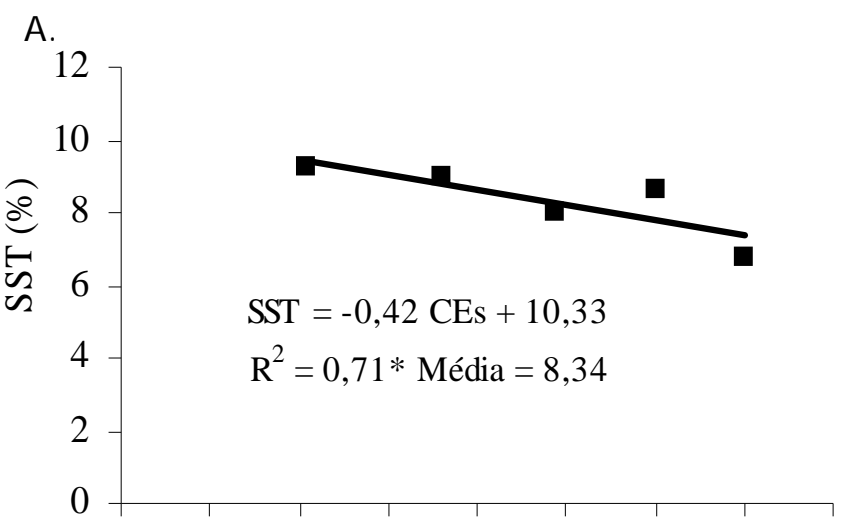

B.

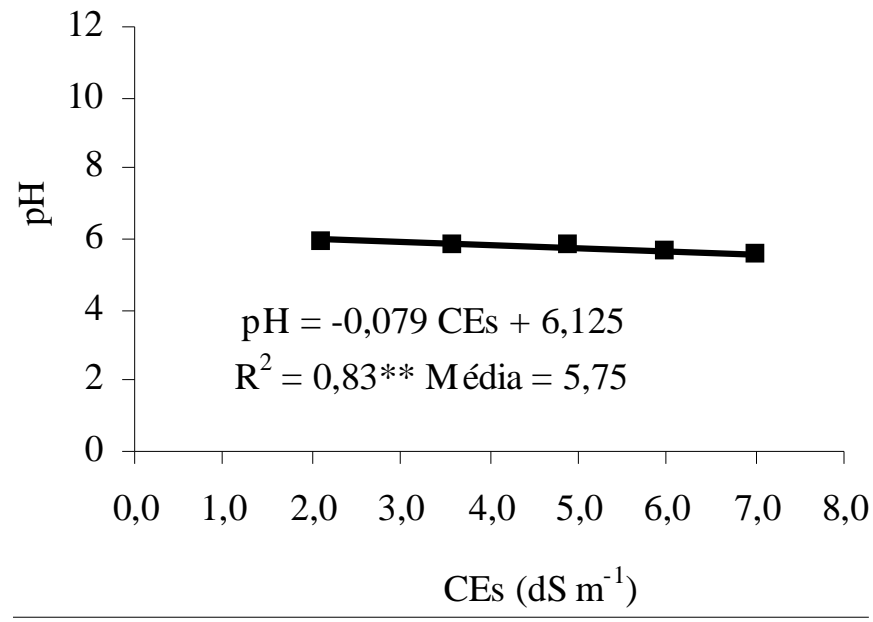

Figura 4. Sólidos solúveis totais (A) e pH (B) absoluto e relativo dos frutos do melão em função da salinidade da solução nutritiva com adição de rejeito salino

ção de primeiro grau, em que se verifica um decréscimo relativo entre $\mathrm{S}_{1}$ e $\mathrm{S}_{5}$ de $29,51 \%$, com ajuste significativo $(\mathrm{p}<0,01)$ e coeficiente de determinação $R^{2}=0,83$ (Figura 4B). Amor et al. (1999) verificaram que a qualidade de frutos do meloeiro foi significativamente afetada pelos níveis de salinidade, sendo que a ATT e o ${ }^{\circ}$ Brix aumentaram enquanto o $\mathrm{pH}$ diminuiu com o aumento da salinidade.

\section{CONCLUSÕES}

1. O incremento da água de rejeito salino no preparo da solução nutritiva reduz linearmente o crescimento e a produção do melão cultivado em fibra de coco a partir da CEs de 2,48 e $1,66 \mathrm{dS} \mathrm{m}^{-1}$ para a matéria seca da parte aérea e o peso médio de frutos, respectivamente.

2. Entre as variáveis analisadas, o peso médio de frutos e área foliar são mais afetadas pelos efeitos da salinidade da solução nutritiva.

3. A água de rejeito da dessalinização, diluída ou não com água de abastecimento, pode ser utilizada no cultivo de melão em sistema hidropônico com reduzida perdas no rendimento dos frutos, permitindo que as águas de boa qualidade, de difícil aquisição e escassez, sejam utilizadas para outros fins.

\section{AGRADECIMENTOS}

Os autores agradecem ao $\mathrm{CNPq}$, pela concessão de recursos financeiros para execução do projeto $(\mathrm{CNPq} /$ Edital Universal 2006, Processo n. 486242/2006-4).

\section{LITERATURA CITADA}

Adams, P. Effects of increasing the salinity of the nutrient solution with major nutrients or sodium chloride on the yield, quality and composition of tomates grown in rockwool. Journal Horticulture Science, v.66, n.1, p.201207, 1991.

Alencar, R. D.; Porto Filho, F. de Q.; Medeiros; J. F. de; Holanda; J. S. de. Crescimento de cultivares de melão amarelo irrigadas com água salina. Revista Brasileira de Engenharia Agrícola e Ambiental, v.7, n.2, p.221-226, 2003.

Amor, F. M. del; Martinez, V.; Cerdá, A. Salinity duration and concentration affect fruit yield and quality, and growth and mineral composition of melon plants in perlite. Journal Horticulture Science, v.34, n.7, p.1234-1237, 1999.

Ayers, R. S.; Westcot, D. W. A qualidade da água na agricultura. Campina Grande: UFPB. Campina Grande: UFPB, 1991. 218p. Estudos FAO: Irrigação e Drenagem, 29.

Binzel, M. L.; Hasegawa, P. M.; Handa, A. K.; Bressan, R. A. Adaptation of tobacco cells to $\mathrm{NaCl}$. Plant Physiology, v.79, n.2, p.118-125, 1985.

Dias, N. S.; Duarte, S. N. Calidad post-cosecha de frutos de melón producidos sobre diferentes niveles de salinidade del suelo y manejos de la fertirrigación en invernadero. Ingeniería del Agua, v.12, n.12, p.119-123, 2005.

Dias, N. da S.; Duarte, S. N.; Medeiros, J. F. de; Teles Filho, J. F. Salinidade e manejo da fertirrigação em ambiente protegido. II: Efeitos sobre o rendimento do meloeiro. Irriga, v.11, n.3, p.376-383, 2006.

Dias, N. da S.; Duarte, S. N; Yoshinaga, R. T.; Teles Filho, J. F. Produção de alface sob diferentes níveis de salinidade do solo. Irriga, v.10, n.1, p.20-29. 2005.

Eloi, W. M.; Duarte, S. N.; Soares, T. M. Níveis de salinidade e manejo da fertirrigação sobre características do tomateiro cultivado em ambiente protegido. Revista Brasileira de Ciências Agrárias, v.2, p.83-89, 2007.

Medeiros, J. F.; Dias, N. da S.; Barros, A. D.de. Manejo da irrigação e tolerância do meloeiro a salinidade da água de irrigação. Revista Brasileira de Ciências Agrárias, v.3, p.242-247, 2008.

Medeiros, J. F. de; Lisboa, R. de A.; Oliveira, M.; Silva Júnior, M. J.; Alves, L. P. Caracterização das águas subterrâneas usadas para irrigação na área produtora de melão da chapada do Apodi. Revista Brasileira de Engenharia Agrícola e Ambiental, v.7, n.3, p.469-472. 2003.

Mickley, M. C. Membrane concentrate disposal: Practices and regulation. Denver: U.S. Department of the Interior. (Desalination and Water Purification Research and Development Program Report N.69). http://www.usbr.gov/pmts/water/media/ pdfs/report069.pdf. 02 Jul. 2004. 
Morais, P. L. D.; Silva, Galdino, G; Maia, E. N.; Menezes, J.B. Avaliação das tecnologias pós-colheita utilizadas e da qualidade de melões nobres produzidos para exportação. Ciência e Tecnologia de Alimentos, v.29, n.1, p.214-218, 2009.

Porto, E. R.; Amorim, M. C. C. de; Dutra, M. T.; Paulino, R. V.; Brito, L. T. de L.; Matos, A. N. B. Uso do rejeito da dessalinização de água salobra para irrigação da erva-sal (Atriplex nummularia). Revista Brasileira de Engenharia Agrícola e Ambiental, v.5, n.1, p.111-114, 2001.

Santos, R. N. C. Avaliação da relação K:N e híbridos de melão em cultivo hidropônico. Piracicaba: ESALQ/USP, 2002. 98p. Dissertação Mestrado
Soares, T. M.; Silva, E. F. F.; Duarte, S. N.; Mélo, R. F.; Jorge, C. A; Bonfim-Silva, E. M. Produção de alface utilizando águas salinas em sistema hidropônico. Irriga, v.12, n.2, p.235-248, 2007.

Soares, T. M.; Silva, I. J. O. da; Duarte, S. N.; Silva, E. F. de F. Destinação de águas residuárias provenientes do processo de dessalinização por osmose reversa. Revista Brasileira de Engenharia Agrícola e Ambiental, v.10, p.730-737, 2006.

Taiz, L.; Zeiger, E. Fisiologia vegetal. 3.ed. Porto Alegre: Artmed, 2006. 719p.

Welles, G.W.H.; Buitelaar, K. Factors affecting soluble solids content of muskmelon (Cucumis melo L.). Netherlands Journal of Agricultural Science, v.36, n.2, p.239-246, 1988. 